\title{
An Exploratory Study of Single and Coupled Lesbian Mothers' Experiences with Social Support
}

\author{
Lara Descartes
}

\begin{abstract}
This exploratory interview study reveals ten lesbian mothers' experiences with different forms of social support. Ten lesbian mothers, five single and five who were part of couples, all with young children and living in southern Ontario, discussed their experiences with emotional, instrumental, and informational support from family, friends and neighbours, the LGBTQ (lesbian, gay, bisexual, transgender, queer/questioning) community, support groups, day cares and schools, health care providers, and online and print resources. Most women had largely positive experiences with family and friends but experienced more variability in the other domains. The mothers' perceptions of potential support sources' acceptance of diversity and efforts at inclusivity particularly influenced their willingness to access organized forms of support. The single lesbian mothers' experiences differed from the coupled lesbian mothers', although there was overlap. Organizations, service providers, and authors providing assistance and information to prospective and current parents are encouraged to continue to increase their awareness of and efforts at including all families.
\end{abstract}

Keywords: Lesbian, Lesbian Couples, Mothers, Single Mothers, Social Support

Lara Descartes is a Professor in Family Studies and Human Development at Brescia University College in London, Ontario. Her current research interests include parenting, LGBTQ+ families, health, and popular culture. Recent publications include Goldman, J., \& Descartes, L. (2016). Food depictions in picture books for preschool children: Frequency, centrality, and affect. Appetite, 96, 203-208. and Blank, T., Descartes, L., \& Asencio, M. (2018). Male patients and their male caregivers. In Y. Kim \& M. J. Loscalzo (Eds.), Gender issues in psycho-oncology (pp. $103-$ 122). New York: Oxford University Press. 


\section{Introduction}

Parenting is an intensive, long-term commitment and those undertaking it face many sources of stress, including emotional, financial, and time-related. Most research has indicated that having access to sources of support helps ease parental stress and that without access to support, parents may be more vulnerable to the negative effects of stressors (Cairney, Boyle, Offord, \& Racine, 2003; Goldberg \& Smith, 2014; Haga, Lynne, Slinning, \& Kraft, 2012; McLeish \& Redshaw, 2017; Östberg \& Hagekull, 2013; Ross, 2005; Shechner, Slone, Meir, \& Kalish, 2010). Types of social support parents may need include emotional (providing a sounding board or sharing good news, for example), instrumental (such as performing child care or picking up children after school), and informational (providing connections or information about health, feeding, day care, and so on) (Collins, Dunkel-Schetter, Lobel, \& Scrimshaw, 1993). Parents' sources of support may include partners or spouses (Crespi, 2001; Haga, et al., 2012; Hyun, et al., 2002), members of families of origin (Hyun, et al., 2002; Tornello, Johnson, \& O’Connor, 2013; Wan, Jaccard, \& Ramey, 1996), and friends (Gameiro, Moura-Ramos, Canavarro, \& Soares, 2011; Maccio \& Pangburn, 2012). Sources of instrumental or informational support can include health care practitioners, parenting groups and books (Haga, et al., 2012; Hjälmhult, Glavin, Økland, \& Tveiten, 2014; Hyun, et al., 2002), and the internet (Hunter, 2015; Lev, et al., 2005; Niela-Vilén, Axelin, Salanterä, \& Melender, 2014; Nieuwboer, Fukkink, \& Hermanns, 2013; Porter \& Ispa, 2013).

Parents who are LGBTQ (lesbian, gay, bisexual, transgender, queer/questioning) experience typical parental stressors and may face additional stressors as well, such as social and/or familial disapproval and isolation (Goldberg, 2012; Goldberg \& Smith, 2011, 2014; Hequemborg, 2004; Holman \& Oswald, 2011; Power et al., 2015; Ross, 2005). In two-parent families, if one parent is biologically related to the child and the other is not, the non-biological parent may face additional challenges, such as lack of social recognition of their parental status (Abelsohn, Epstein, \& Ross, 2013; Dalton \& Bielby, 2000; Gartrell, et al., 2000; Hequemborg, 2004; Patterson, Hurt, \& Mason, 1998). Research specific to LGBTQ parents has indicated that social support is important to their well-being (Goldberg \& Smith, 2008; Goldberg \& Smith, 2011; Ross, 2005) and, for couples, facilitates relationship satisfaction (Blair \& Holmberg, 2008; Sumontha, Farr, \& Patterson, 2016; Vyncke \& Julien, 2007). Outside of urban areas, however, with their greater concentrations of LGBTQ individuals, it can be difficult to find such support, especially at the institutional level (Holman \& Oswald, 2011; Power et al., 2014).

A survey of a United States sample reported that nearly one-third of lesbians are parents (Pew Research Center, 2013). This sizeable fraction underscores the importance of understanding the parenting and support experiences of lesbian mothers. Some studies conducted with lesbian mothers in two-parent families have indicated that many have satisfying experiences with social support from family and friends (Almack, 2008; Bos, Van Balen, \& Van Den Boom, 2004; Gartrell, et al., 2000). Research also, however, has indicated that lesbian mothers do not always have positive experiences with potential support sources, whether families of origin, friends, health care staff, or textual (Almack, 2008; Bergstrom-Lynch, 2016; Cherguit, Burns, Pettle, \& Tasker, 2013; Dalton \& Bielby, 2000; DeMino, Appleby, \& Fisk, 2007; Descartes, 2016; Gartrell, et al., 2000; Hayman, Wilkes, Halcomb, \& Jackson, 2013; Levy, 1996; O’Neill, Hamer, \& Dixon, 2012; Power et al., 2015). 
The author, herself a single lesbian mother, began this exploratory research with an interest in hearing and giving voice to other single lesbian mothers' experiences involving perceptions and receipt of social support. This interest included how these might vary from or overlap those of lesbian mothers who are members of couples. The descriptor lesbian is used throughout this paper as most of the research participants self-identified as that term. The rest identified as queer ${ }^{1}$. The terms heterosexual and straight are used interchangeably. "Single" is used to describe parents who were parenting entirely or primarily on their own. "Coupled" describes a co-parenting situation in which the parents were married or in a committed partnership with each other. This differentiation in the type of lesbian-headed family structure is important. As one set of scholars noted, "twoparent families ... have greater opportunities for social networks as a result of combined ties from each of the couple" (Shechner, et al., 2010, p. 289). Single mothers raise their children on one female (and thus likely to be comparatively low (U.S. Bureau of Labor Statistics, 2010; Statistics Canada, 2018)) income and juggle the time and energy demands of family life by themselves. Single mothers arguably thus have access to fewer resources than coupled mothers. This is of concern as single lesbian mothers (SLMs) have the same trials of living in a heteronormative society as coupled lesbian mothers (CLMs). Single mothers face additional challenges inherent to living in a social environment pervaded by a two-parent family ideology (Nelson, 2006; Smith, 1993).

\section{Methodology}

The research design and analysis were informed by a grounded theory approach (Charmaz, 2006; Strauss \& Corbin, 1997, 1998). This approach foregrounds research participants' descriptions and explanations of their own lives. As in-depth interviews are ideal for "research where respondents' experience is analysed with the uncovering of its thematic dimensions in view" (Crouch \& McKenzie, 2006, p. 488), these were selected as the research method. Initial domains of inquiry were set through very general, open-ended questions such as "Tell me what it's been like being a single lesbian mother" and "What kind of support do you have available to you?" The author's prior knowledge of social support literature provided probes regarding types of support: emotional, instrumental, and informational, and the various sources of it, such as family members, friends, or community groups. Beyond the initial general questions and probes, the approach to data collection was flexible, with research participants able to follow their own threads of interest during the interview. The principle of discovery was incorporated, as themes raised in early interviews were included in subsequent interview as probes if they did not arise on their own. Support was one of the domains that the women had quite a bit to say about, and the probes helped provide categories for comparison (for example, regarding sources such as parents, friends, and the LGBTQ community) as did the women's narratives (for example, sources of support such as day care staff and health care providers). Comparison of experiences with support within and between categories of mother (single and coupled) continued throughout the data analysis. Literature searches during analysis also provided data, primarily about coupled lesbian mothers' support experiences, as there is little literature specific to single lesbian mothers.

\footnotetext{
1 "Queer" is a broader term than lesbian. It incorporates people who identify outside of traditional sexual and/or gender identities.
} 
The research site was southern Ontario, Canada. The social context of being lesbian in Ontario includes that same-sex marriage has been legal in Ontario since 2003, and Canada has an international reputation of being very LGBTQ-friendly (Spartacus Blog, 2018). Despite this, heterosexism and homophobia still exist (see, for example, Hunter, 2015), and sexual identityrelated hate crimes still occur (Statistics Canada, 2015). Moreover, in Ontario, although universal health care exists, many of the expenses associated with assisted reproduction are not covered (Ontario Ministry of Health and Long-Term Care, 2016), making the procedures quite costly. This is a form of institutionalized discrimination that disproportionately affects those with low incomes and/or access to just one income.

Recruitment advertisements were distributed through digital newsletters serving lesbians and queer women in southern Ontario and via postings in locales such as coffee shops and bookstores, over a period from 2011-2014. The age of the respondents' children was restricted to under 18 to limit the discussion to current and recent parenting experiences of minor children. Interviews were conducted with ten lesbian mothers total, five of whom were single. There were few single mother responses to the ads. There is no way to know why the response was low. The size of the actual population is unknowable, so the response rate is also. Interviews also were conducted with five coupled lesbian mothers. More coupled than single mothers replied to the recruitment efforts and the first five with minor children who were successfully scheduled were the ones who were interviewed.

Interview data from a sixth single lesbian mother were excluded from this analysis. This woman had been married to a man for many years. She had conceived and raised her children with him, and only recently gotten divorced and come out as lesbian. Her children were older than the other mothers'. This woman's concerns primarily were about being newly out and forming a lesbian identity, making her conversation topics different enough from the other SLMs' that the author felt it best to omit her data.

The sample size of ten may concern some, but Mira Crouch and Heather McKenzie (2006) argue that the concept "sample" is actually not a useful consideration for exploratory work such as that presented here where "respondents are not drawn (i.e. sampled) from a "target population"" (p. 492), and "rather than being systematically selected instances of specific categories of attitudes and responses ... respondents embody and represent meaningful experience-structure links" (p. 493). Crouch and McKenzie contend that small numbers of respondents are not a failing of this type of qualitative work, as it should not be expected to be generalizable: "it is in the nature of exploratory studies to indicate rather than conclude" (p. 492). They argue that for such studies, small numbers actually are preferable as "it is much more important for the research to be intensive, and thus persuasive at the conceptual level, rather that aim to be extensive with intent to be convincing, at least in part, through enumeration" (2006, p. 494).

All the SLMs participating in this research had utilized donors to become pregnant. Three used donors from a clinic and two used known donors (acquaintances who agree to provide sperm for the purposes of conception). Two SLMs were dating women who were not their parenting partners. All the CLM participants' children were donor-conceived. One couple used a donor from a clinic and four used known donors. Three of the interviewed CLMs were the birth mothers of one or more of their children and two were non-birth mothers.

Four of the SLMs had one child and the other had two. Three CLMs had one child and two 
had two children. All the women's children were aged ten and under at the time of the interview. The majority of the SLM and CLM mothers were non-Latina White women who had become mothers in their thirties and forties. The exceptions were two non-Latina White SLMs who gave birth in their late twenties and one SLM who was not non-Latina White. Of the five SLMs, two had incomes above $\$ 60,000$ per year, two were between $\$ 20,000-40,000$, and one was not reported. The lowest annual household income among the CLMs was in the $\$ 60,000-80,000$ range, one was in the $\$ 100,000-150,000$ range, and three were over $\$ 150,000$. Nearly all the SLMs and CLMs lived in an urban or suburban area. The two who did not were within an hour's drive of one.

All interviews were conducted by the author and audio recorded. Seven of the interviews were conducted in-person and three were conducted on Skype due to issues of scheduling and/or geographical distance. The author is a non-Latina White SLM who gave birth in her late thirties to a donor-conceived child. The author thus shared one or more identity aspects with all the research participants. Conversation before, during, and after interviews often involved areas of common ground. Rapport seemed easy to establish with most research participants, although the Skype interviews were somewhat more stilted than the in-person interviews. Informed consent information was provided at the beginning of the interview and basic demographic data were collected at the end. As a thank you for the women's time, $\$ 40$ gift cards to a bookstore chain were provided for their participation.

Interviews were transcribed by alumnae from the author's institution and the transcripts were categorized and summarized by the author. In the Results section, participants' quotes are given verbatim, although extraneous fillers ("you know," "like," etc.) have been removed. Some words or phrases were edited out for conciseness, clarity, or for confidentiality. Absences are indicated by ellipses or brackets containing the author's substitutions.

\section{Results}

Informal and formal support sources discussed below are categorized into: family of origin, friends and neighbours, the LGBTQ community, support groups, day cares and schools, health care providers, and online and print resources. The types of support are labelled, whether emotional, instrumental, or informational. Both positive and negative support experiences are discussed. In some instances, whether a woman was "out" as a lesbian in various venues impacted her support experiences and so that information is included where relevant. All the women were out to family and close friends, but the situation varied more for neighbours, schools, and so forth.

\section{Family of Origin}

Family members were discussed by SLMs and CLMs as primarily providing emotional and instrumental support. The single lesbian mothers all had one or more emotionally supportive relatives and they kept in regular contact with those family members. Only one SLM spoke of ongoing conflict with her parents before and after her child's birth, saying that having a child "probably actually even disengaged me from my own not-so-great parents even more." She could rely on other relatives for emotional support, however. In contrast, another SLM told of how her baby's arrival healed a rift between her and her parents: "I wasn't speaking to my parents because 
we had a bad kind of history ... [but post-baby] I'm like "Oh! Raising children is hard!” So, I've kind of gotten over it, but at first we were very alienated." Two SLMs lived geographically close to family of origin members, but only one relied regularly on family for instrumental support. Due to her own irregular work schedule, she purposefully had moved near her parents for child care assistance, leaving her friendship circle behind. Two other women's mothers provided occasional help when needed, but they lived farther away and their help was utilized primarily in emergency situations. The fifth SLM did not live near her family of origin and did not report receiving instrumental support from them.

The coupled lesbian mothers all spoke of positive family relationships, with almost all the women talking about one or more close, emotionally supportive ties on one or both sides. Two women mentioned, however, that the non-birth mother's mother felt that her role in the child's life and relationship to the child were poorly defined. For at least one CLM, those difficulties led to tensions with her mother-in-law. This CLM also noted that "sometimes I sense that with them, especially [my mother-in-law], she doesn't see us as much of a valid family as maybe her kids that are in heterosexual relationships." One non-biological CLM, however, related how the arrival of their baby had brought more acceptance for her relationship from her own mother.

None of the CLMs were immediately proximal to their families of origin but all had at least one partner's family an hour to an hour-and-a-half away. Two of the women's mothers provided child care in emergency situations. One CLM with family of origin just over an hour away lamented, however, that "I have to be honest, it's hard not having family in town. It's not the same relying on friends or trying to rely on friends."

\section{Friends and Neighbours}

The SLMs and CLMs mostly spoke of friends as providing emotional and instrumental support. Three SLMs did not have extensive local friend networks. Two of these women had relocated to make parenthood easier: one to be near her parents and one to obtain a better-paying job. Both spoke of friend groups they had left behind. Although all had at least one lesbian friend, these three had comparatively few proximal lesbian friends. The other two SLMs spoke of larger friend networks on which they could rely for emotional and instrumental support. One had relocated to be closer to this friend network when she had her baby but noted that they were not always reliable: "it started feeling like more work to ask for support than just deal with being on my own." All the SLMs were friends with one or more heterosexual parents of young children. One mother stated that after her children were born, "I began to relate much more really with heterosexual single mothers." She lived near two straight single mothers and the three women supported each other emotionally and with tasks such as after-school pick-up. Of the SLMs, this mother received the most regular instrumental help from friends. She had lived in her locale for many years and had more than one friend network.

Three of the SLMs mentioned that they were not close to their neighbours. They thought their neighbours assumed they were heterosexual and this seemed to cause some discomfort for two of the women. One talked about how awkward she felt around her new neighbours because 
"there are sometimes occasions where I don't get read as queer because I'm single." So even in her interactions with neighbours she perceived to be lesbian, "there's not mutual acknowledgement [of us both being lesbian.]"

Two SLMs, however, expressed relief at being able to pass as heterosexual in some situations, such as around neighbours they considered conservative and/or to spare their child from others' judgements. One mother said, speaking of herself and the author:

We could look straight, like people wouldn't know. So, we're really invisible. So, in a way, we could use that to our advantage because we can hide our minority status when we want to ... But in a way it's also hard because it's invisible ... you're treated as though you're privileged when you're not.

Among coupled lesbian mothers, a few mentioned that their friendship groups altered after the birth of their children. One woman explained, "I didn't even care about friendships actually, I kind of went very internal, you know? So, it was quite a big shift to our friendships." Despite this, most of the CLMs described fairly extensive friend groups, comprised of different sexual identities, who provided emotional and occasional instrumental help such as child care. One woman described how "[my partner's] got an enormous amount of friends and people that help out if we need [it]." The regularity of such support depended on proximity: friends who lived nearby were much more likely than those farther away to provide aid. Two CLMs had roommates either currently or previously who provided significant help with tasks such as child care and endof-day child pick-up. Two of the CLMs had strong ties with neighbourhood friends who provided instrumental support if needed.

Three CLMs stated that they had high comfort levels living as out lesbians in their neighbourhoods and noted that other gay or lesbian couples and families lived near them. One mother reported that "our closest neighbourhood friends are a same-sex two mom family with two kids and that has been huge for our . . . support for everything, from . . . them lending us their conception book to everything . . . every step of the way." Only one CLM spoke of being misidentified as straight by neighbours. This mother stated that she chose not to challenge that assumption, as she felt the neighbours were conservative and she wanted to protect her child from their judgements.

\section{LGBTQ Community}

LGBTQ community groups provide venues to meet and socialize with other LGBTQ people, and thus are potential sources of emotional and informational support. Four of the single mothers discussed being less active in LGBTQ community groups and activities than they were before the births of their children and expressed a desire to increase their involvement. Most did not attend many, if any, organized activities or visit specifically LGBTQ venues. The women's level of community involvement thus was minimal, although one was a member of an LGBTQ 
group that met monthly. She noted, however, that many LGBTQ events cost money that she did not have, so she did not attend. Four women spoke of related difficulties meeting other lesbians for friendship or dating. One mother stated:

I feel like I don't get much interaction with the lesbian community other than my playgroup and they're all married ... I don't really go out to the gay bars, and I don't really know what else people do ... There's [a local LGBTQ event] that's once a year, and otherwise I'm not in with the social scene, really.

Three of the CLMs also talked about being more active in the LGBTQ community, and generally more social, pre-motherhood. One mother said: "we really were part of the community," but "when you have kids your circle is very small so we aren't really much part of the lesbian community, gay community." None seemed very distressed by this change, although one mother expressed this concern: "I wish that [my daughter] spent time with more queer families. That to me is something that I feel sad about." As noted above, most of the CLMs had a circle of lesbian friends, usually couples, with whom they socialized regularly.

\section{Support Groups}

Four of the single lesbian mothers actively sought information on various types of structured groups after the births of their children, looking for emotional and/or informational support. Perhaps uncoincidentally, the only SLM who did not was the only one to receive frequent support from her geographically proximal family. Three SLMs had significant concerns about the composition of the support groups they investigated and/or attended. These concerns were such that two of the women did not even try to attend groups in which they were interested. If the groups were comprised of mothers in general, the women feared they might be outsiders since the other mothers likely would be heterosexual. If the groups were comprised specifically of lesbian mothers, the women's concern was that the other mothers would not be single. As one woman put it, "I've actually been really reluctant to join the queer parenting stuff. I've talked to people on the phone or whatever but as much as I like hearing "Oh, we're open to single[-parent] families," I don't totally buy it." This mother experienced frustration trying to find support while dealing with postpartum depression: "I feel like I have to tell people that I'm queer 100 times and somehow they think that that's not actually a factor and it $i s$, like it factors into decisions to do moms' groups or to access resources." Another mother had a similarly unsatisfactory time seeking support for intimate partner violence. She investigated a group but did not attend as the group was not lesbianspecific. This mother stated simply, "I don't feel comfortable."

Despite the SLMs' concerns, a few did find some organized sources of support, even if it was not in the form they would have preferred. One woman sporadically attended a single mothers' group that was mostly made up of heterosexual women. Another attended an LGBTQ social group, although it was not for parents specifically. One SLM found an informal group of CLMs. She 
noted that there were differences between her and their experiences, as the other women were coupled and wealthier than her, but she enjoyed being with them. This woman also tried a mothers' support group but said it was comprised solely of coupled straight women who were too politically different from her for her to feel at ease.

The coupled lesbian mothers did not speak of making similar efforts as the SLMs to find support groups and did not express negative feelings about support groups' compositions. None of the interviewed CLMs reported attending any groups, but there were three mentions of their partners doing so. One briefly attended a local breastfeeding group, another went to an LGBTQ parenting group for a short while before it dissolved, and one attended a local mothers' group comprised of heterosexual women. According to her partner, this CLM enjoyed the group, was out as a lesbian, and felt welcomed by the other mothers.

\section{Day Cares and Schools}

Day cares and schools are institutional sources of instrumental and informational support. Two of the SLMs were on maternity leave, so they were not yet involved in day care. Both, however, had thought about whether or not to be open about their sexual identities to their eventual day care providers, with one unsure, saying "I don't want . . . my reluctance to be sort of out in those spaces to affect [my child] and ... I do want to be out in those spaces and I want that to be okay for her." The other new mother did plan to be out at her child's day care, and went to an LGBTQ community center for information on affirming day cares. Her eventual choice was made for geographical convenience, however, rather than pro-LGBTQ policies. The other three SLMs chose not to disclose their sexual identity at their child's school or day care, although one woman with an ex-partner noted the day care staff knew she had been in a lesbian relationship. She indicated that she felt the staff had been uncomfortable about that. She and one of the other nondisclosing SLMs were not very involved at their children's day cares, or with the staff. The third non-disclosing mother ("I don't mention [my sexual identity]") indicated that she was involved at her child's school. Her perception was that school personnel assumed she was a heterosexual, divorced single mother.

Coupled lesbian mothers had a different situation, as both mothers' names were on their children's "approved to pick up" lists and it was common knowledge among staff that their families were headed by two women. One CLM did mention that other parents in the school did not necessarily know. Four CLMs purposively discussed their family configurations with their children's teachers or care providers. The women described positive interactions with school/day care staff overall. One mother said of her child's care center: "They've been pretty good. There are definitely other queer families that use them." Another woman related how her new day care provider acknowledged that they were her first lesbian-headed family and proactively asked her "What do you want me to say to the other kids when they ask?" A third CLM said that her child's care center was similarly attentive to their family's needs: "They said "Is there anything we can do?" and I said "Can you talk about different families?"' When some staff at the center demonstrated ignorance regarding same-sex families, there was administrative response and diversity training. 


\section{Health Care Providers}

Before and after their children were conceived most of the single lesbian mothers reported straightforward experiences with health care providers and clinicians, who are important, institutional sources of instrumental support and information. The SLMs noted that their sexual identities were not necessarily known in every venue. One mother, however, who was out with her health care providers as both lesbian and single experienced quite a bit of difficulty. She was the one who stated: "I feel like I have to tell people that I'm queer 100 times and somehow they think that that's not actually a factor and it is." She indicated that lip service was paid to inclusivity but that in actuality any needs specific to her identity were ignored. Another SLM noted that a childbirth preparation class advertised for single women was taught by a married woman and did not deal with single women's issues at all. She raised her concern with the group leader and felt shut down:

[I] went to this prenatal class for single parents and it was never mentioned that we were single . . . I actually at the very end got really frustrated because ... [ the group leader] had never brought it up and on the last day she still wasn't bringing it up, so I actually said "I feel like it's the elephant in the room" and she goes "Oh well, I'm sorry you feel that way," she goes, "but the curriculum is exactly the same."

The CLMs indicated that their identities as same-sex couples were apparent in health care settings such as doctors' offices or childbirth preparation classes. Although as a group most of the CLMs had largely positive experiences with most staff members, there were several incidents that made some uncomfortable. One mother told this story of a childbirth class:

We went to the first childbirth class and it was very heteronormative, that's the gentle way of saying it. There was lots of "Well, the dad will do this" and "The father will do this" and [it] felt really like it wasn't a good fit for me. So, I emailed the woman who was . . . [in charge] and I said "You know, this part isn't working for us." I asked the woman to use the word partner and basically the response was "Well, [the instructor's] not going to do that. She'll sometimes throw a partner here or there basically to appease you, but ..." So. I said we weren't going to finish the class.

This mother also had unpleasant experiences in a doctor's office when, despite explanations, the staff repeatedly referred to her child's donor as a father. Another CLM had a negative encounter when she and her wife brought their child to a hospital, where a doctor repeatedly queried "Well, which one is the mom? I can only talk to the mom." The mothers 
eventually told the physician that one was the child's mother and one was the child's aunt so that the medical consultation could go forward. Two CLMs specifically sought out LGBTQ-friendly medical venues to try to ensure positive experiences for their families and seemed largely content with the encounters they had there.

\section{Online and Print Resources}

All the SLMs spent time online, and three found useful connections and information that way, such as in a blog written by a single lesbian mother and message boards sponsored by a local mothers' group. Two mentioned that parenting and birthing books were disappointing, with books aimed at a general audience assuming that their readers were heterosexual and books aimed at lesbians assuming they were coupled. This made them feel somewhat excluded. Interestingly, both women who critiqued these books and their language were the youngest of the respondents and had the lowest incomes. Both mothers mentioned that the books generally did not speak to people of varying socioeconomic statuses.

Coupled lesbian mothers did not mention seeking resources online or in print as frequently as SLMs did, or of being disappointed by the content. One spoke of borrowing parenting books from another CLM, one was in contact with her mothers' group online, and one was a member of a local lesbian information electronic mailing list. This was the extent of CLMs' reports of their online and print information- and connection-seeking.

\section{Discussion}

Both the single and coupled lesbian mothers indicated they had a largely supportive network of family and friends, albeit levels of satisfaction varied with individual relationships. SLMs and CLMs generally reported obtaining emotional support from their family and friend networks, although a few coupled lesbian mothers described tension around family members not recognizing their relationships and roles, such as that of the non-biological mother, as valid (Dalton \& Bielby, 2000; Gartrell, et al., 2000; Patterson, Hurt, \& Mason, 1998). Several women described changes in their friend networks after they became parents, with a post-baby network comprised largely of other parents, many of whom were heterosexual (Gartrell, Rodas, Deck, Peyser, \& Banks, 2006). Friends and family who were proximal were the most likely to provide mothers with instrumental support. Neighbours are proximal geographically but were not identified as significant support sources by most of the women. The women most positive about their neighbours were those who lived near women like themselves; the SLM who lived near other single mothers and the CLMs who lived near lesbian couples.

The family and friend networks the coupled women described tended to be larger than those of the single women, likely due at least in part to the presence of two people to create and maintain social ties (Shechner, et al., 2010). Most CLMs lived near at least one partner's family and were friends with other coupled lesbians. Most of the single mothers in this study were more isolated than the coupled women. Only one relied regularly and frequently on family and as a 
group the SLMs were more likely to live farther away from family than were the CLMs. The friend networks of at least three of the SLMs seemed comparatively small. For two of the women this was likely connected to their recent relocations.

Day cares and schools generally provided supportive environments for the mothers and their children, although not all the single lesbian mothers were out in these settings. Without a female partner to provide a cue, SLMs reported they often were misidentified as heterosexual in various venues. This caused some discomfort for at least three. Lena Dominelli states that the "identity of the individual, whether as subject or object of other people's definitions, is enacted through the social relations in which they both engage" (2002, p. 40). To be lesbian but not to be recognized as lesbian can be a stressor (see Power et al., 2014) and research has shown, that for women, being "out" is associated with mental well-being (Pachankis, Cochran, \& Mays, 2015). This makes it unfortunate that the sexual identities of the SLMs in particular were obscured by others' heteronormative presumptions. This sometimes had the result of adversely colouring the women's feelings about those interactions and increasing their feelings of isolation (Descartes, 2016).

Single lesbian mothers had more choice than coupled lesbian mothers about how much others knew about their sexual identities, however. In non-intimate settings, such as in the neighbourhood, day cares, and schools, some SLMs purposefully did not disclose their sexual identities. This could cause ambivalence, but the women saw a positive in that the non-disclosure might spare their children discomfort if neighbours or staff were perceived as unaccepting of lesbian identity. One CLM similarly spoke of relief, for her child's sake, at being misidentified by neighbours as straight. This misidentification was less common for the CLMs than the SLMs, as the CLMs shared a home, were both on legal forms concerning the children, and often attended meetings and appointments together. Heteronormative reactions to disclosure of their lesbian identities could result in its own stress, which was mostly noted as arising in health care venues (Abelsohn, Epstein, \& Ross, 2013; Cherguit, et al., 2013; Hayman, et al., 2013; Hunter, 2015; Levy, 1996; von Doussa, et al., 2016). Some staff had difficulty accepting the presence of two female parents and the nonexistence of a male parent.

Neither SLMs nor CLMs reported much involvement in the LGBTQ community, but this was of greater concern to the SLMs, who as a group were more isolated, than the CLMs. Single lesbian mothers and coupled lesbian mothers differed in the extent to which they sought connections and information from formal support groups and online and print resources. The SLMs were more likely to devote energy and time to those pursuits, seeking a community that for the most part eluded them. They were thwarted by feeling like outsiders: resources for single women appeared to target presumptively heterosexual women and groups and resources aimed at lesbian mothers seemed to assume such women were in coupled relationships (Descartes, 2016). These feelings prevented some of the SLMs from participating in organized groups that might have been sources of support.

A major difference between the SLMs and the CLMs was access to resources, both social and financial, and the disparity likely explained some of the greater isolation experienced by the SLMs. For one, as noted, the social networks of couples are likely to be larger than single people's, and the partners have each other to rely on. The presence of a second parent to watch a child can offer more freedom for one partner to engage in external activities. Two people may have access 
to two incomes rather than one, so it may be more possible to hire child care if needed. These factors may help explain why SLMs were more likely than CLMs to speak of spending time looking for print and online resources, as any support found there would not require going out or paying for child care.

A theme that emerged from the interviews of both SLMs and CLMs was that the "one size fits all" approach to designing curricula and materials for parenting classes and health care resources did not work well and could be a source of significant discomfort to them. Presumptive sameness was experienced by the women as problematic, for it left their identities unrecognized and their needs unaddressed. Three examples were the health care system that could not acknowledge how sexual identity and family structure might shape one woman's health care needs differently than another's, a prenatal class advertised for single women that did not address issues specific to single women, and a childbirth preparation class that assumed parents were heterosexual (the persistence of this particular problem is evinced by Eileen Levy recording it back in 1996). The women found these types of situations disturbing enough that some dropped out of or did not attend programming.

\section{Future Directions and Implications}

This was an exploratory study, conducted with a small, homogenous, self-selected group. A report from the United States indicates that Black and Latina lesbians are about twice as likely as non-Latina White lesbians to have children (Cahill, 2009), yet all but one of the research participants was non-Latina White. Most of the women had fairly high incomes, and their support networks, experiences, and stressors likely differ from those of women living with fewer economic resources. Families also are formed in diverse ways that may affect their support networks and stressors, and the interviews discussed here did not include women with children from prior heterosexual relationships, or those who were adoptive or foster parents. Finally, the support needs of lesbian-headed families, whether coupled or single, can be affected by ex-partners, ex-spouses, and/or known donors, and that was not addressed here. One SLM and one CLM talked about expartners, speaking of distress associated with the ex-partners' activities. Other women discussed the known donors they had used, with an SLM experiencing stress connected to her donor's actions, and one couple receiving a great deal of support from their donor. This information indicates a need for future research that includes such aspects of racial, ethnic, and socioeconomic diversity as well as of differences in family formation, structure, and dynamics.

Although the set of women participating in this exploratory research was homogenous and small, and the results thus are not generalizable, the emergent themes are worth consideration. These include a need for awareness of the true range of family diversity among the authors of conception and parenting books aimed at LGBTQ individuals, and also those aimed at more general audiences. This awareness should extend to the designers of birthing and parenting curricula, health care providers (von Doussa, et al., 2016), and other clinicians. A unifying theme in the SLMs' and CLMs' narratives was that assumptions are still made in these venues that there is a certain type of normative, expectable family: one father, one mother, and their child/ren. The 
family forms of the interviewed women were sometimes questioned by others, especially in medical settings, in ways that could be very distressing. That made acquiring needed support and information difficult.

The themes in the single lesbian mothers' narratives also indicate a need for support tailored to their specific needs. All the SLMs sought support and information in print and online. Most had looked for community in the form of support groups and desired more LGBTQ-specific connections. There simply were not resources or activities, however, that seemed to include people of their demographic profile. The parenting books and online sources the women accessed did not acknowledge them as an audience. The mothers' groups available to them were not perceived as a good fit, and a few decided to not attend, feeling that their needs would not be recognized. LGBTQ community organizations could perform outreach aimed specifically at single parents and authors of books and websites aimed at LGBTQ parents could do more to acknowledge that some people do not have partners. The information given by the SLMs participating in this research also reflected the fact that single parents generally have less access to social and financial resources than coupled parents. Such constraints need consideration by those planning outreach and support services.

\section{Conclusion}

This paper presented interview results from a small-scale exploratory study of ten lesbian mothers, five single and five coupled, all of whom had donor-conceived children aged ten and under. The mothers generally had emotionally and sometimes instrumentally supportive family relationships and most, especially the coupled lesbian mothers, had friends on whom they could rely. The institutions the mothers interacted with varied as to their degree of supportive inclusivity in their services. At the schools and day cares where mothers were known to be lesbian, there seemed to be awareness of and support for diversity among families. Clinicians, support groups, and online/print resources, however, were not as inclusive or supportive as they could be, and when challenged, institutional members seemed resistant to change. The single lesbian mothers did not feel they fit into support groups and felt unacknowledged by informational resources. Some coupled lesbian mothers reported difficulty in some health care settings. Greater recognition of the existence of and more outreach to single mothers by the LGBTQ community would help such issues, as would greater awareness of family structural diversity by parenting resource and curricula authors and those working in the health care fields.

\section{Acknowledgement}

The author would like to acknowledge the funding for this project that came from Brescia University College and the excellent transcribing of Ms. Nicola Lord and Ms. Katelyn Harris. 


\section{References}

Abelsohn, K. A., Epstein, R., \& Ross, L. E. (2013). Celebrating the "other" parent: Mental health and wellness of expecting lesbian, bisexual, and queer non-birth parents. Journal of Gay \& Lesbian Mental Health, 17, 387-405.

Almack, K. (2008). Display work: Lesbian parent couples and their families of origin negotiating new kin relationships. Sociology, 42, 1183-1199. https://doi.org/10.1177/0038038508096940

Bergstrom-Lynch, C. (2016). Lesbians, Gays, and Bisexuals Becoming Parents or Remaining Childfree: Confronting Social Inequalities. New York: Lexington Books.

Blair, K., \& Holmberg, D. (2008). Perceived social network support and well-being in same-sex versus mixed-sex romantic relationships. Journal of Social and Personal Relationships, 25, 769791.

Bos, H. M. W., Van Balen, F., \& Van Den Boom, D. C. (2004). Experience of parenthood, couple relationship, social support, and child-rearing goals in planned lesbian mother families. Journal of Child Psychology and Psychiatry, 45, 755-764.

Cahill, S. (2009). The disproportionate impact of antigay family policies on Black and Latino same-sex couple households. Journal of African American Studies, 13, 219-250.

Cairney, J., Boyle, M., Offord, D. R., \& Racine, Y. (2003). Stress, social support and depression in single and married mothers. Social Psychiatry and Psychiatric Epidemiology, 38, 442-449.

Charmaz, K. (2006). Constructing Grounded Theory: A Practical Guide Through Qualitative Analysis. Los Angeles: Sage.

Cherguit, J., Burns, J., Pettle, S., \& Tasker, F. (2013). Lesbian co-mothers' experiences of maternity health care services. Journal of Advanced Nursing, 69, 1269-1278.

Collins, N. L., Dunkel-Schetter, C., Lobel, M., \& Scrimshaw, S. C. (1993). Social support in pregnancy: Psychological correlates of birth outcomes and postpartum depression. Journal of Personality and Social Psychology, 65, 1243-1258.

Crespi, L. (2001). And baby makes three: A dynamic look at development and conflict in lesbian families. Journal of Gay and Lesbian Psychotherapy, 4, 7-30.

Crouch, M., \& McKenzie, H. (2006). The logic of small samples in interview-based qualitative research. Social Science Information, 45, 483-499. DOI: 10.1177/0539018406069584. 
Dalton, S. E., \& Bielby, D. D. (2000). “That's our kind of constellation”: Lesbian mothers negotiate institutionalized understandings of gender within the family. Gender and Society, 14, 36-61.

DeMino, K. A., Appleby, G., \& Fisk, D. (2007). Lesbian mothers with planned families: A comparative study of internalized homophobia. American Journal of Orthopsychiatry, 77, 165173.

Descartes, L. (2016). Single lesbian mothers. In M. Motapanyane (Ed.), Motherhood and lone/single parenting: A 21st century perspective (pp. 193-204). Bradford, ON: Demeter Press.

Dominelli, L. (2002). Anti-oppressive Social Work Theory and Practice. Hampshire, England: Palgrave Macmillan.

Gameiro, S., Moura-Ramos, M., Canavarro, M. C., \& Soares, I. (2011). Network support and parenting in mothers and fathers who conceived spontaneously or through assisted reproduction. Journal of Reproductive and Infant Psychology, 29, 170-182.

Gartrell, N., Banks, A., Reed, N., Hamilton, J., Rodas, C., \& Deck, A. (2000). The National Lesbian Family Study: 3. Interviews with mothers of five-year-olds. American Journal of Orthopsychiatry, 70, 542-548.

Gartrell, N., Rodas, C., Deck, A., Peyser, H., \& Banks, A. (2006). The USA National Lesbian Family Study: 4. Interviews with mothers of 10-year-olds. Feminism and Psychology, 16, 175192.

Goldberg, A. E. (2012). Gay Dads: Transitions to Adoptive Fatherhood. New York: New York University Press.

Goldberg, A. E., \& Smith, J. Z. (2008). The social context of lesbian mothers' anxiety during early parenthood. Parenting, 8, 213-239.

Goldberg, A. E., \& Smith, J. Z. (2014). Predictors of parenting stress in lesbian, gay, and heterosexual adoptive parents during early parenthood. Journal of Family Psychology, 28, 125137.

Goldberg, A. E., \& Smith, J. Z. (2011). Stigma, social context, and mental health: Lesbian and gay couples across the transition to adoptive parenthood. Journal of Counseling Psychology, 58, 139-150.

Haga, S. M., Lynne, A., Slinning, K., \& Kraft, P. (2012). A qualitative study of depressive symptoms and well-being among first-time mothers. Scandinavian Journal of Caring Sciences, $26,458-466$. 
Hayman, B., Wilkes, L., Halcomb, E. J., \& Jackson, D. (2013). Marginalised mothers: Lesbian women negotiating heteronormative health care services. Contemporary Nurse: A Journal for the Australian Nursing Profession, 44, 120-127.

Hequemborg, A. (2004). Unscripted motherhood: Lesbian mothers negotiating incompletely institutionalized family relationships. Journal of Social and Personal Relationships, 21, 739-762.

Hjälmhult, E., Glavin, K., Økland, T., \& Tveiten, S. (2014). Parental groups during the child's first year: An interview study of parents' experiences. Journal of Clinical Nursing, 19/20, 29802989.

Holman, E. G., \& Oswald, R. F. (2011). Nonmetropolitan GLBTQ parents: When and where does their sexuality matter? Journal of GLBT Family Studies, 7, 436-456.

Hunter, A. (2015) Lesbian mommy blogging in Canada: Documenting subtle homophobia in Canadian society and building community online, Journal of Lesbian Studies, 19, 212-229. DOI: $10.1080 / 10894160.2015 .969077$

Hyun, O., Lee, W., Yoo, A., Cho, B., Yoo, K., Miller, B. C., . . Lau, S. (2002). Social support for two generations of new mothers in selected populations in Korea, Hong Kong, and the United States. Journal of Comparative Family Studies, 33, 515-528.

Lev, A. I., Dean, G., De Filippis, L., Evernham, K., McLaughlin, L., \& Phillips, C. (2005). Dykes and tykes: A virtual lesbian parenting community. Journal of Lesbian Studies, 9, 81-94.

Levy, E. F. (1996). Reproductive issues for lesbians. Journal of Gay and Lesbian Social Services, 5, 49-58. DOI: 10.1300/J041v05n01_0

Maccio, E. M., \& Pangburn, J. A. (2012). Self-reported depressive symptoms in lesbian birth mothers and comothers. Journal of Family Social Work, 15, 99-110.

McLeish, J., \& Redshaw, M. (2017). Mothers' accounts of the impact on emotional wellbeing of organised peer support in pregnancy and early parenthood: A qualitative study. BMC Pregnancy and Childbirth, 17, 1-14.

Nelson, M. K. (2006). Single mothers “do" family. Journal of Marriage and Family, 68, 781795.

Niela-Vilén, H., Axelin, A., Salanterä, S., \& Melender, H. (2014). Internet-based peer support for parents: A systematic integrative review. International Journal of Nursing Studies, 51, 15241537. 
Nieuwboer, C. C., Fukkink, R. G., \& Hermanns, J. M. A. (2013). Peer and professional parenting support on the internet: A systematic review. CyberPsychology, Behavior and Social Networking, 16, 518-528.

O’Neill, K. R., Hamer, H. P., \& Dixon, R. (2012). 'A lesbian family in a straight world': The impact of the transition to parenthood on couple relationships in planned lesbian families. Women's Studies Journal, 26(2), 39-53.

Ontario Ministry of Health and Long-Term Care. (2016). OHIP claims for fertility services and the Ontario Fertility Program. Retrieved from http://www.health.gov.on.ca/en /pro/programs/ohip/bulletins/11000/bul11162.pdf on January 16, 2019.

Östberg, M., \& Hagekull, B. (2013). Parenting stress and external stressors as predictors of maternal ratings of child adjustment. Scandinavian Journal of Psychology, 54, 213-221.

Pachankis, J. E., Cochran, S. D., \& Mays, V. M. (2015). The mental health of sexual minority adults in and out of the closet: A population-based study. Journal of Consulting and Clinical Psychology, 83, 890-901.

Patterson, C. J., Hurt, S., \& Mason, C. D. (1998). Families of the lesbian baby boom: Children's contact with grandparents and other adults. American Journal of Orthopsychiatry, 68, 390-399. DOI:10.1037/h0080348.

Pew Research Center. (2013). A survey of LGBT Americans: Attitudes, experiences and values in changing times. Washington, DC: Pew Research Center.

Porter, N., \& Ispa, J. M. (2013). Mothers' online message board questions about parenting infants and toddlers. Journal of Advanced Nursing, 69, 559-568.

Power, J., Brown, R., Schofield, M. J., Pitts, M., McNair, R., Perlesz, A., \& Bickerdike, A. (2014). Social connectedness among lesbian, gay, bisexual, and transgender parents living in metropolitan and regional and rural areas of Australia and New Zealand. Journal of Community Psychology, 42, 869-889.

Power, J., Schofield, M. J., Farchione, D., Perlesz, A., McNair, R., Brown, R., . . Bickerdike, A. (2015). Psychological wellbeing among same-sex attracted and heterosexual parents: Role of connectedness to family and friendship networks. Australian and New Zealand Journal of Family Therapy, 36, 380-394.

Ross, L. E. (2005). Perinatal mental health in lesbian mothers: A review of potential risk and protective factors. Women and Health, 41, 113-128. 
Shechner, T., Slone, M., Meir, Y., \& Kalish, Y. (2010). Relations between social support and psychological and parental distress for lesbian, single heterosexual by choice, and two-parent heterosexual mothers. American Journal of Orthopsychiatry, 80, 283-292.

Smith, D. (1993). The Standard North American Family: SNAF as an ideological code. Journal of Family Issues, 14, 50-65.

Spartacus Blog. (2018). Spartacus Gay Travel Index. Retrieved January 16, 2019 from https://spartacus.gayguide.travel/blog/spartacus-gay-travel-index-2018/.

Statistics Canada. (2015). Police-reported hate crime in Canada, 2013. Retrieved January 16, 2019 from https://www150.statcan.gc.ca/n1/pub/85-002-x/2015001/article/14191-eng.htm\#a20.

Statistics Canada. (2018). The gender wage gap and Equal Pay Day, 2018. Retrieved January 15, 2019 from https://www150.statcan.gc.ca/n1/pub/89-28-0001/2018001/article/00010-eng.htm.

Strauss, A. \& Corbin, J. (Eds.). (1997). Grounded Theory in Practice. Thousand Oaks: Sage.

Strauss, A., \& Corbin, J. (1998). Basics of Qualitative Research Techniques and Procedures for Developing Grounded Theory ( $2^{\text {nd }}$ ed.). Thousand Oaks: Sage.

Sumontha, J., Farr, R. H., \& Patterson, C. J. (2016). Social support and coparenting among lesbian, gay, and heterosexual adoptive parents. Journal of Family Psychology, 30, 987-996.

Tornello, S. L., Johnson, S. M., \& O’Connor, E. (2013). Relationship quality among lesbian mothers in planned families. Journal of GLBT Family Studies, 9, 346-363.

U.S. Bureau of Labor Statistics. (2010). Highlights of women's earnings in 2009. Report 1025, June 2010. Washington, DC: U.S. Bureau of Labor Statistics.

von Doussa, H., Power, J., McNair, R., Brown, R., Schofield, M., Perlesz, A., . . Bickerdike, A. (2016). Building healthcare workers' confidence to work with same-sex parented families.

Health Promotion International, 31, 459-469.

Vyncke, J. D., \& Julien, D. (2007). Social support, coming out, and adjustment of lesbian mothers in Canada and France. Journal of GLBT Family Studies, 3, 397-424.

Wan, C. K., Jaccard, J., \& Ramey, S. L. (1996). The relationship between social support and life satisfaction as a function of family structure. Journal of Marriage and Family, 58, 502-513. 